\title{
Spontaneous Remissions and Medical Miracles -The Role of Divinity in the Future of Medicine
}

\author{
Richard Sarnat* \\ Chief Medical Officer, Advanced Medicine Integration Group, USA
}

Submission: May 21, 2018; Published: May 25, 2018

*Corresponding author: Richard L Sarnat, Chief Medical Officer, Advanced Medicine Integration Group, L.L.C, Highland Park, Illinois 60035, USA, Email: rsarnat@amibestmed.com

\begin{abstract}
There is a growing awareness in the world of disease management and managed care that our conventional medical paradigm for the treatment of chronic diseases is failing. Poor clinical outcomes and escalating utilization of expensive high technology, high cost solutions have created an opportunity to revisit and reassess the effectiveness and rationale of our conventional paradigms and their heavy reliance on pharmaceuticals, surgery and medical devices as first line treatment options. While a new paradigm emphasizing patient centric care, self management and an interdisciplinary approach, which utilizes providers of all licensures is becoming more common, the far horizon of this paradigm shift is even more revolutionary, as it questions "what is the role of Divinity in medical science?"
\end{abstract}

Keywords: Spontaneous remissions; Medical miracles; Master John Douglas; Angelic reformation.

Abbreviations: CAM: Complementary and Alternative Medicine; TCM: Traditional Chinese Medicine.

\section{Introduction}

In an effort to improve both clinical outcomes and control medical costs, medical science has recently become more open to investigating the use of alternative medical modalities, such as yoga, meditation, Tai Chi and Energy Medicine, as well as increasing the utilization of the more established and already licensed disciplines of chiropractic, acupuncture, massage therapy and Naturopathy.

Utilization of these modalities in an interdisciplinary model is now the recommended paradigm for many disease states, many of which fall into the chronic pain and addiction arena. The recent acceptance and increased utilization of these complementary and alternative medicine (CAM) modalities delivered by their state licensed providers within the mainstream of conventional medicine is a paradigm shift still in evolution [1-10]. However, the more profound and existential horizon of this paradigm shift is the yet unexplored domain of the role of Divinity within medical science.

As an integrative medical doctor active in the managed care arena who has practiced transcendental meditation, hatha yoga and tai chi for over 45 years, this evolution of our conventional medical model to a more patient centric, self-managing interdisciplinary model is, in my opinion, long overdue and not surprising. I predict that this trend of the inclusion of CAM modalities across the continuum of care will continue to grow, as more clinical and cost outcomes data on their effectiveness becomes published [11-13].

What I find even more interesting, however, is that by including these more consciousness based modalities into our health care system we are now approaching the junction point where science and spirituality must meet and reckon with each other. Since the infamous split of mind and body by Rene Descartes, this moment of reckoning has been gathering momentum, heralded by the paradigm shift to mind/body medicine we are now witnessing. But this is only the first step of reconciling the truth of how our universe is constructed and understanding the nature and design of our place within the Whole.

Many consciousness based modalities, such as yoga, meditation, tai chi and energy medicine all aim to correct an imbalance that exists as the root cause of a given patients disease state. The fundamentals of Ayur-Veda and Traditional Chinese Medicine (TCM) attempt to restore proper balance to a physiology struggling with a world filled with environmental toxins, non-nutritious food, impure water and the sensory overload typical of the new millennia. But at the deepest healing level, these traditional medical systems reconnect the patient with their Divine Self, with their God, by teaching consciousnessbased, self improvement techniques which allow the patient to 
transcend beyond the human construction of their intellect, mind and emotions. This is the true goal of yoga and meditation - to provide true knowledge of the Divine Self and its primacy in the universe. This is the fundamental experience which is the "aha moment" and provides the foundation for lasting selfcorrection and healing to occur.

Each of these traditional medical systems and their treatment modalities inch us forward to rebalance and greater health, as we make better lifestyle choices more suited to our dosha (in Ayur Veda) or rebalance our chi in TCM. But it is my opinion, as a longtime researcher into miraculous healings and spontaneous remissions that we have just begun to scratch the surface of an entirely new body of knowledge, which is totally capable of transforming most everything we thought we knew as factual. And after all, isn't that what science is all about? If the history of science has taught us anything, it is that at any given moment in time, we are mostly deluded about the scientific laws underlying the nature of our reality and the causation of disease in particular.

I recently published what I believe to be the first scientific report on miraculous healings, attributed to the teachings of Master John Douglas and the technique he calls "Angelic Reformation" [14]. While "miraculous healings" of various disease states have been scientifically reported previously, the exact mechanism, which allow for these seeming miracles or spontaneous remissions have been poorly understood. By contrast, the mechanism of action underlying the "miraculous healings" in the three case studies just reported: Sarcoidosis, Chronic Lyme disease and Fibromyalgia seems to be understood with greater clarity, as these case reports are representative of the many hundreds of case studies I have documented over a ten-year period while observing the work of Master John Douglas and the graduates of his Elite Development course. The Elite Development course is offered to medical and nonmedical applicants alike. To this date approximately 350 graduates have been taught a technique which allows them to transcend the humanly constructed left-brain, emotions, intellect and even subconscious mind and connect to their Divinity which underlies all levels of the human construct. As this level of consciousness and the nervous system undergoes the process, which Master John Douglas calls "angelic reformation," then one can access what Master John Douglas calls "truth in nature" the ability to measure the electromagnetic wave form emanating from each particle of creation. Analogous to possessing knowledge of the unique molecular weight of each substance in the periodic table, this ability allows the Elite Development course graduate to recognize the hidden laws, which govern our universe and the hidden infectious disease life forms, which are completely unknown to medical science and yet are potentially the root cause of many of our idiopathic diseases. Or, as Master John Douglas says, "this knowledge and ability allows one to hear the song of creation and thereby know yourself and your God and all the laws which control the manifestation of all that we see."

\section{Conclusion}

While this is an inspiring vision of things to come, admittedly all of these discoveries must ultimately be subjected to more rigorous scientific methodology. Yet, the sheer number of miraculous healings I have observed and the fact that this body of knowledge can be taught to others who obtain similarly effective results is very exciting, given the rising worldwide prevalence of idiopathic chronic diseases and the growing microbial resistance to antibiotics.

\section{Conflicts of Interest}

I declare no conflicts of interest in this work.

\section{Short Biographies}

Richard L. Sarnat M.D. is the co-founder and Chief Medical Officer of Advanced Medical Integration Group located in Highland Park, Illinois. This twenty-year old managed care company has a national presence and is a national leader in the evolution of the newly developing paradigm of integrative medicine. While originally trained as an ophthalmologic surgeon with a high volume surgical practice, Dr. Sarnat wanted to pursue population-based solutions to improve the clinical and cost outcomes, which were eluding his large multispecialty medical group. He looks forward to increasing the evidence base on the mechanisms of action, which allow miraculous healings to become the norm as the future of medicine evolves.

\section{References}

1. Suchowersky O, Gronseth G, Perlmutter J, Reich S, Zesiewicz T, et al. (2006) Practice Parameter: neuroprotective strategies and alternative therapies for Parkinson disease (an evidence-based review): report of the Quality Standards Subcommittee of the American Academy of Neurology. Neurology 66(7): 976-982.

2. Lee MS, Lam P, Ernst E (2008) Effectiveness of tai chi for Parkinson's disease: a critical review. Parkinsonism Relat Disord 14(8): 589 -594.

3. Lee MS, Ernst E (2009) Qigong for movement disorders: A systematic review. Mov Disord 24(2): 301-303.

4. Lee MS, Shin BC, Kong JC, Ernst E (2008) Effectiveness of acupuncture for Parkinson's disease: a systematic review. Mov Disord 23(11): 15051515.

5. Eisenberg DM (2005) The Institute of Medicine report on complementary and alternative medicine in the United States-personal reflections on its content and implications. Altern Ther Health Med 11(3): 10-15.

6. Astin JA, Shapiro SL, Eisenberg DM, Forys KL (2003) Mind-body medicine: state of the science, implications for practice.

7. J Am Board Fam Pract 16(2): 131-147.

8. Jonas WB, Eisenberg D, Hufford D, Crawford C (2013) The evolution of complementary and alternative medicine (CAM) in the USA over the last 20 years. Forsch Komplementmed 20(1): 65-72.

9. Lutz A, Jha AP, Dunne JD, Saron CD (2015) Investigating the phenomenological matrix of mindfulness-related practices from a neurocognitive perspective. Am Psychol 70(7): 632-658.

10. Marciniak R, Sheardova K, Cermakova P, Hudecek D, Sumec R, et al. (2014) Effect of meditation on cognitive functions in context of aging and neurodegenerative diseases. Front Behav Neurosci 8: 17. 
11. Schneider RH, Grim CE, Rainforth MV, Kotchen T, Nidich SI, et al. (2012) Stress reduction in the secondary prevention of cardiovascular disease: randomized, controlled trial of transcendental meditation and health education in Blacks. Circ Cardiovasc Qual Outcomes 5(6): 750-758.

12. Sarnat RL, Winterstein J, Cambron JA (2007) Clinical utilization and cost outcomes from an integrative medicine independent physician association: an additional 3-year update. J Manipulative Physiol Ther 30(4): 263-269.
13. Sarnat RL, Winterstein J (2003) Clinical and cost outcomes of an integrative medicine IPA. J Manipulative Physiol Ther 27(5): 336-347.

14. Herman PM, Poindexter BL, Witt CM, Eisenberg DM (2012) Are complementary therapies and integrative care cost-effective? A systematic review of economic evaluations. BMJ Open 2(5).

15. Sarnat R (2018) Miraculous healings of chronic lyme disease fibromyalgia and sarcoidosis without the use of pharmaceuticals or antibiotics. OBM Integrative and Complementary Medicine 3(2): 003.

\section{Your next submission with Juniper Publishers} will reach you the below assets

- Quality Editorial service

- Swift Peer Review

- Reprints availability

- E-prints Service

- Manuscript Podcast for convenient understanding

- Global attainment for your research

- Manuscript accessibility in different formats

( Pdf, E-pub, Full Text, Audio)

- Unceasing customer service

ack the below URL for one-step submission

https://juniperpublishers.com/online-submission.php 